\title{
Methotrexate and gemcitabine combination chemotherapy for the treatment of malignant pleural mesothelioma
}

\author{
KOZO KURIBAYASHI $^{1 *}$, SHIGERU MIYATA ${ }^{1 *}$, KAZUYA FUKUOKA $^{1}$, AKI MURAKAMI $^{1}$, \\ SYUSAI YAMADA $^{1}$, KUNIHIRO TAMURA $^{1}$, NORIKO HIRAYAMA ${ }^{1}$, TAKAYUKI TERADA $^{1}$, \\ CHIHARU TABATA ${ }^{1}$, YOSHIHIRO FUJIMORI ${ }^{2}$ and TAKASHI NAKANO ${ }^{1,2}$ \\ ${ }^{1}$ Division of Respiratory Medicine, Department of Internal Medicine; \\ ${ }^{2}$ Cancer Center, Hyogo College of Medicine, Nishinomiya, Hyogo 663-8501, Japan
}

Received December 15, 2012; Accepted April 9, 2013

DOI: $10.3892 / \mathrm{mco} .2013 .118$

\begin{abstract}
Malignant pleural mesothelioma (MPM) is an aggressive tumor of serosal surfaces with a poor prognosis. Methotrexate and gemcitabine have exhibited single-agent activity in MPM. We evaluated the feasibility of sequential administration of these agents in the treatment of MPM. A total of 21 patients with MPM received a 30-min infusion of $100 \mathrm{mg} / \mathrm{m}^{2}$ methotrexate and, $30 \mathrm{~min}$ later, a 30-min infusion of $800 \mathrm{mg} / \mathrm{m}^{2}$ gemcitabine. Twenty-four hours following the administration of methotrexate, leucovorin rescue therapy was initiated $\left(10 \mathrm{mg} / \mathrm{m}^{2}\right.$ leucovorin administered 4 times at 6-h intervals). These treatments were administered weekly, with 4 weekly administrations constituting a cycle of therapy. A total of 88 cycles were administered to the 21 patients, with each patient receiving 1-10 cycles (median, 4.2 cycles). Eight patients (38.1\%) exhibited a partial response, 10 patients $(47.6 \%)$ had stable disease and 3 patients (14.3\%) had progressive disease. The median overall survival was 19.4 months (range, 02-41 months). One-year and 2-year survival rates were 61.9 and $38.1 \%$, respectively. Hematological toxicity was considered acceptable, with grade 3-4 toxicities occurring in 3 (14.3\%) patients. Non-hematologic toxicity was generally mild. There was no treatment-related mortality. Our results suggest that methotrexate and gemcitabine combination therapy is feasible and effective in the treatment of MPM. This regimen may offer an alternative to platinum-based chemotherapy and a prospective trial including a larger cohort of patients is recommended to confirm these results.
\end{abstract}

Correspondence to: Dr Yoshihiro Fujimori, Cancer Center, Hyogo College of Medicine, 1-1 Mukogawa-cho, Nishinomiya, Hyogo 663-8501, Japan

E-mail: fuji-y@hyo-med.ac.jp

*Contributed equally

Key words: malignant mesothelioma, chemotherapy, methotrexate, gemcitabine

\section{Introduction}

Malignant pleural mesothelioma (MPM) arises from the mesothelial surface of the pleural cavity and is a locally invasive tumor with poor prognosis $(1,2)$. In $>70 \%$ of patients, the tumor is associated with exposure to asbestos fibers following a long latent period of 20-50 years (3). The incidence of mesothelioma is rare in the general population; however, it is expected to increase in the next 20 years in industrialized countries as a result of past asbestos use $(4,5)$.

MPM is refractory to the currently available treatment options. The efficacy of surgical therapy has not been precisely defined (6) and radiotherapy may be palliative but does not prolong survival (7). For the majority of patients with MPM, systemic chemotherapy remains the standard of care (8). Prior to 2003, the majority of studies on chemotherapy for MPM were conducted using either single agents or combination regimens in the setting of small phase II trials. The results demonstrated $<20 \%$ of tumor regression with no significant effect on patient survival, which was 6-9 months $(8,9)$. Since 2003, the combination of cisplatin and pemetrexed (PTX) has been used as standard chemotherapy for MPM (10). This was based on a randomized phase III study in which PTX plus cisplatin achieved a response rate of $41.3 \%$ and a median survival of 12.1 months, compared to $16.7 \%$ response rate and 9.3-month median survival achieved by cisplatin alone (10).

In this study, a non-platinum-based combination therapy with two anti-metabolites (methotrexate and gemcitabine) was devised. Methotrexate is an analogue of folic acid known to be effective against breast cancer, lymphoblastic leukemia and osteosarcoma $(11,12)$. Gemcitabine is a pyrimidine analogue, effective against a wide range of solid tumors, including pancreatic carcinoma and non-small cell lung carcinoma (13). Methotrexate and gemcitabine have been reported to exhibit single-agent activity in MPM $(8,9)$; however, the combined administration of these agents has not yet been investigated.

In the present study, we evaluated the feasibility and efficacy of methotrexate and gemcitabine combination therapy in the treatment of MPM, through the analysis of toxicity, response and survival data. 


\section{Patients and methods}

Patients. Patients with histologically confirmed MPM who had previously received $0-1$ chemotherapy cycles, not including gemcitabine and methotrexate, were considered eligible for this single-center study. Tumor extension was classified according to the tumor-node-metastasis (TNM) staging system developed by the International Mesothelioma Interest Group (IMIG) (14). Patients were 18-75 years of age, with an Eastern Cooperative Oncology Group (ECOG) performance status of 0-2, had adequate bone marrow function (hemoglobin concentration $\geq 10 \mathrm{~g} / \mathrm{dl}$, total leukocyte count $\geq 3.0 \times 10^{9} / 1$, granulocyte count $\geq 1.5 \times 10^{9} / 1$ and platelet count $\left.\geq 100 \times 10^{9} / 1\right)$, adequate renal function (serum creatinine level $<1.5 \mathrm{mg} / \mathrm{dl}$ ) and adequate hepatic function (total bilirubin level $\leq 1.5$ times the upper limit of normal and serum alanine transferase and alkaline phosphatase levels $\leq 3$ times the upper limit of normal). Patients with a concurrent malignancy of another type or symptoms and/or signs of metastases in the central nervous system were excluded. Patients with prior surgery were considered eligible. This study was approved by the Institutional Review Board of Hyogo College of Medicine and informed consent was obtained from each patient.

Treatment. Patients received a 30-min intravenous (i.v.) infusion of $100 \mathrm{mg} / \mathrm{m}^{2}$ methotrexate and, $30 \mathrm{~min}$ later, a 30-min i.v. infusion of $800 \mathrm{mg} / \mathrm{m}^{2}$ gemcitabine. For leucovorin rescue, calcium leucovorin $\left(10 \mathrm{mg} / \mathrm{m}^{2}\right.$, p.o. or i.v. $)$ was administered 4 times at 6-h intervals, initiated $24 \mathrm{~h}$ after the administration of methotrexate. These treatments were administered weekly, with 4 treatments constituting a cycle of therapy. A maximum of 6 cycles were administered, unless therapy was terminated due to tumor progression, patient death or wish of treatment discontinuation, or in the presence of convincing evidence that further treatment was not beneficial. Antiemetic and symptomatic treatments were permitted. Analyses of blood cell count and chemistry were performed weekly. Treatment was delayed in the case of i) absolute neutrophil count $<1.5 \times 10^{9} / 1$ and/or platelet count $<100 \times 10^{9} / 1$; ii) any grade 3 or 4 non-hematological toxicity (except for nausea/vomiting) that did not resolve to grade 1 or less. If these toxicities were not resolved within the cycle, the dose was reduced to $75 \%$ of the previous dose level for the next cycle.

Response and toxicity criteria. Chest imaging by computed tomography (CT) was performed at baseline, following completion of every other treatment cycle and every 8 weeks following completion of therapy. Objective response was evaluated and calculated using the modified Response Evaluation Criteria in Solid Tumors (RESIST) criteria for MPM (15). Treatmentrelated toxicities were evaluated according to the National Cancer Institute Common Toxicity Criteria version 3.0 (16).

Statistical analysis. Survival was calculated as the time period from treatment initiation to death, using the Kaplan-Meier method (17).

\section{Results}

Patient characteristics. The characteristics of the 21 eligible patients are listed in Table I. There were 16 males and 5 females,
Table I. Patient characteristics.

\begin{tabular}{lc}
\hline Characteristics & No. $(\%)$ \\
\hline Gender & \\
Male & $16(76.2)$ \\
Female & $5(23.8)$ \\
Age, years & \\
Median & 63 \\
Range & $51-75$ \\
Performance status & \\
0 & $1(4.8)$ \\
1 & $12(57.1)$ \\
2 & $8(38.1)$ \\
IMIG stage & \\
Ib & $1(4.8)$ \\
II & $1(4.8)$ \\
III & $4(19.0)$ \\
IV & $15(71.4)$ \\
Histological subtype & \\
Epithelial & $17(81.0)$ \\
Sarcomatous & $3(14.3)$ \\
Biphasic & $1(4.7)$ \\
Previous treatment & \\
None & $10(47.6)$ \\
Surgery & $2(9.5)$ \\
Chemotherapy & $9(42.9)$ \\
Asbestos exposure & \\
Yes & $13(61.9)$ \\
No & $8(38.1)$ \\
\hline
\end{tabular}

IMIG, International Mesothelioma Interest Group.

with a median age of 63 years (range, 51-75 years). The histological pattern of MPM was epithelial in 17 cases, sarcomatous in 3 cases and biphasic in 1 case. Nineteen patients (90.4\%) had stage III and IV disease according to the IMIG staging system at the time of enrollment. Thirteen patients (61.9\%) had an ECOG performance status of 0 or 1.

Responses to treatment. A total of 88 cycles were administered to the 21 patients. Each patient received a median 4.2 cycles (range, 2-10 cycles). Response to chemotherapy is shown in Table II. No patients exhibited a complete response. Eight patients (38.1\%) exhibited a partial response. According to the histological pattern, a PR was observed in 6 out of the 17 patients with epithelial type and in 2 out of the 3 patients with sarcomatous type MPM. Out of the total 21 patients, 10 (47.6\%) had stable disease and $3(14.3 \%)$ had progressive disease with no period of stabilization.

Toxicity. The toxicity observed in each patient is shown in Table III. There was no treatment-related mortality. The most frequently observed hematological side effects were neutropenia and thrombocytopenia. Grade 3-4 hematologic 
Table II. Response to chemotherapy and histologic subtype.

\begin{tabular}{|c|c|c|c|c|}
\hline \multirow[b]{2}{*}{ Response } & \multirow[b]{2}{*}{$\begin{array}{l}\text { Overall } \\
\text { no. }(\%)\end{array}$} & \multicolumn{3}{|c|}{ Histologic subtype } \\
\hline & & $\begin{array}{c}\text { Epithelial } \\
\text { no. (n) }\end{array}$ & $\begin{array}{c}\text { Sarcomatous } \\
\text { no. (n) }\end{array}$ & $\begin{array}{c}\text { Biphasic } \\
\text { no. (n) }\end{array}$ \\
\hline Complete response & 0 & 0 & 0 & 0 \\
\hline Partial response & $8(38.1)$ & 6 & 2 & 0 \\
\hline Stable disease & $10(47.6)$ & 8 & 1 & 1 \\
\hline Progressive disease & $3(14.3)$ & 3 & 0 & 0 \\
\hline
\end{tabular}

Table III. Chemotherapy-related toxicity in eligible patients.

\begin{tabular}{|c|c|c|c|c|}
\hline Toxicity & $\begin{array}{l}\text { Grade } 1 \\
\text { no. }(\%)\end{array}$ & $\begin{array}{l}\text { Grade } 2 \\
\text { no. }(\%)\end{array}$ & $\begin{array}{l}\text { Grade } 3 \\
\text { no. }(\%)\end{array}$ & $\begin{array}{l}\text { Grade } 4 \\
\text { no. }(\%)\end{array}$ \\
\hline Hematologic & 5 & $2(9.5)$ & $2(9.5)$ & $1(4.8)$ \\
\hline Gastrointestinal & $5(23.8)$ & $1(4.8)$ & $0(0)$ & $0(0)$ \\
\hline Hepatobiliary & $4(19.0)$ & $3(14.3)$ & $0(0)$ & $0(0)$ \\
\hline Pulmonary & $0(0)$ & $2(9.5)$ & $0(0)$ & $0(0)$ \\
\hline
\end{tabular}

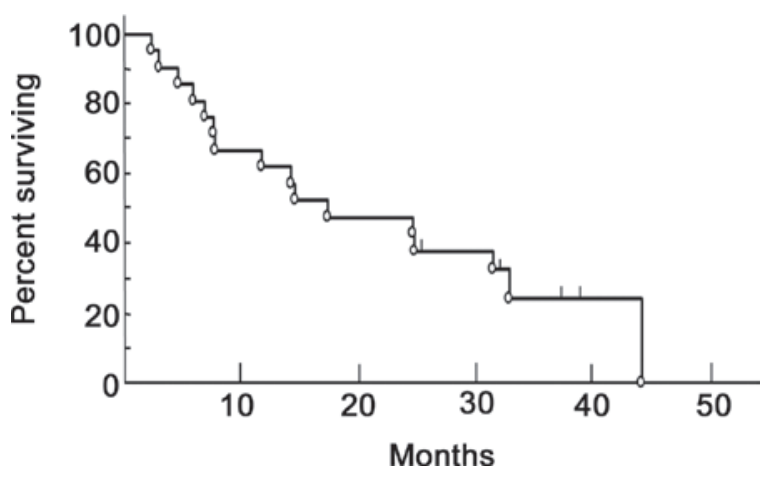

Figure 1. Overall survival.

toxicities were observed in 3 patients (14.3\%), which, however, were manageable and did not result in life-threatening complications. Six patients (28.6\%) experienced grade 1-2 gastrointestinal toxicities (nausea, vomiting and anorexia) and 7 patients (33.3\%) developed grade 1-2 liver dysfunction. Two patients developed interstitial pneumonitis (grade 2) and were administered glucocorticosteroid therapy.

Survival. The median overall survival was 19.4 months (range, 2-41 months), with a 1- and 2-year survival rates of 61.9 and $38.1 \%$, respectively (Fig. 1). As regards the histological pattern, the median survival was 19.6 months for the epithelial, 22.6 months for the sarcomatous and 7.1 months for the biphasic type of MPM.

\section{Discussion}

MPM is notoriously refractory to the majority of treatments and the standard first-line treatment is currently cisplatin and PTX chemotherapy (10). In the present study, we evaluated the feasibility of a non-platimum regimen for MPM, involving the sequential administration of the anti-metabolites, methotrexate and gemcitabine.

Methotrexate, an antifolate, has long been used as an anticancer agent and exerts its action through the inhibition of dihydrofolate reductase (DHFR) (12). High-dose methotrexate $\left(1500 \mathrm{mg} / \mathrm{m}^{2}\right)$ has been reported to be effective in the treatment of MPM, with a response rate of 37\% (18). However, high-dose methotrexate was associated with severe toxicity and this method of treatment has been abandoned. The efficacy of low- or medium-dose methotrexate has not been assessed in MPM. In the treatment of gastric cancer (19) and head and neck cancer (20), weekly administration of medium-dose methotrexate $\left(100-200 \mathrm{mg} / \mathrm{m}^{2}\right)$ combined with sequential administration of 5-fluorouracil (5-FU) $\left(600 \mathrm{mg} / \mathrm{m}^{2}\right)$ has been reported to be effective and of low toxicity. In this study, a moderate dose of methotrexate $\left(100 \mathrm{mg} / \mathrm{m}^{2}\right)$ was administered weekly in combination with gemcitabine.

PTX is a newly developed antifolate that targets multiple enzymes involved inDNA synthesis and folate metabolism. Single use of PTX has been reported to be moderately effective against MPM (21). Following combination therapy with $1,250 \mathrm{mg} / \mathrm{m}^{2}$ gemcitabine administered on days 1 and 8 and $500 \mathrm{mg} / \mathrm{m}^{2} \mathrm{PTX}$ administered on day 8 or 1 , chemotherapy-naïve MPM patients exhibited a response rate of $17-26 \%$, with a median survival of 8-10 months (22). Hematologic toxicities included grade 3-4 neutropenia $(60 \%)$ and febrile neutropenia (10\%). These results indicated that the combination of PTX and gemcitabine was moderately effective in MPM patients but was associated with a notably high incidence of neutropenia (22).

In this study on the methotrexate and gemcitabine doublet regimen, 3 patients (14.3\%) exhibited grade 3-4 hematologic toxicity, with no sepsis or hemorrhage. There was no observed grade 3-4 non-hematological toxicity. Two patients developed interstitial pneumonitits (grade 2) which responded well to 
steroid therapy. Thus, the tolerability and toxicity profiles were considered acceptable.

The response rate with the methotrexate and gemcitabine combination chemotherapy was $38.1 \%$, which is within the range of $20-50 \%$ observed with other 'active' agents for MPM $(8,10)$. Median survival was 19.4 months. Antifolates may be one of the key agents for MPM, since the majority of mesothelioma cells of all histological MPM subtypes express high-affinity $\alpha$ folate receptor (23). In our combination regimen, we observed that methotrexate, an old-type antifolate, exhibited desirable efficacy. Methotrexate has also been reported to be more efficient compared to PTX, a newly developed antifolate, against osteosarcoma cells (24), indicating that methotrexate possesses a therapeutic potential.

In the present study, 10 out of the 21 patients were chemotherapy-naïve and their response rate to this regimen was similar to the overall response rate described above. This suggests that methotrexate plus gemcitabine may be beneficial as the first-line treatment for MPM. Eleven patients who had been previously treated also exhibited a response rate similar to the overall response rate. Although the optimal regimen constituting the second-line chemotherapy remains to be determined, results of the present study suggest that methotrexate plus gemcitabine may also be beneficial as a second-line treatment.

In conclusion, the present study demonstrated that the methotrexate and gemcitabine combination therapy is feasible, with a more favorable toxicity profile and efficient in the treatment of MPM. Further clinical evaluation is required, with prospective trials including a larger cohort of patients.

\section{References}

1. Robinson BW, Musk AW and Lake RA: Malignant mesothelioma. Lancet 366: 397-408, 2005.

2. Nakano T: Current therapies for malignant pleural mesothelioma. Environ Health Prev Med 13: 75-83, 2008.

3. Wagner JC, Slegg CA and Marchand P: Diffuse pleural mesothelioma and asbestos exposure in North western Cape Province. Br J Ind Med 17: 260-271, 1960.

4. Kaufman AJ and Pass HI: Current concepts in malignant pleural mesothelioma. Expert Rev Anticancer Ther 8: 293-303, 2008.

5. Yang H, Testa JR and Carbone M: Mesothelioma epidemiology, carcinogenesis, and pathogenesis. Curr Treat Options Oncol 9: 147-57, 2008.

6. Maziak DE, Gagliardi A, Haynes AE, Mackay JA and Evans WK: Surgical management of malignant pleural mesothelioma: a systematic review and evidence summary. Lung Cancer 48: $157-169,2005$
7. Ung YC, Yu E, Falkson C, Haynes AE, Stys-Norman D and Evans WK: The role of radiation therapy in malignant pleural mesothelioma: a systematic review. Radiother Oncol 80: 13-18, 2006.

8. Steele JPC and Klabatsa A: Chemotherapy options and new advances in malignant pleural mesothelioma. Ann Oncol 16: 345-351, 2005.

9. FennellDA,Gaudino G,O'Byrne KJ,MuttiL and van Meerbeeck J: Advances in the systemic therapy of malignant pleural mesothelioma. Nat Clin Pract Oncol 5: 136-147, 2008.

10. Vogelzang NJ, Rusthoven JJ, Symanowski J, et al: Phase III study of pemetrexed in combination with cisplatin versus cisplatin alone in patients with malignant pleural mesothelioma. J Clin Oncol 21: 2636-2644, 2003.

11. Huennekens FM: The methotrexate story: a paradigm for development of cancer chemotherapeutic agents. Adv Enzyme Regul 34: 397-419, 1994.

12. McGuire JJ: Anticancer antifolates: current status and future directions. Curr Pharm Des 9: 2593-2613, 2003.

13. Lund B, Kristjansen P and Hansen H: Clinical and preclinical activity of 2',2'-difluorodesoxycitidine (Gemcitabine). Cancer Treat Rev 19: 45-55, 1993.

14. Rusch VW: A proposed new international TNM staging system for malignant pleural mesothelioma. From the International Mesothelioma Interest Group. Chest 108: 1122-1128, 1995.

15. Byrne MJ and Nowak AK: Modified RECIST criteria for assessment of response in malignant pleural mesothelioma. Ann Oncol 15: 257-60, 2004.

16. National Cancer Institute Common Toxicity Criteria for Adverse Events version 3.0. http://ctep.cancer.gov/reporting/ctc.html: Accessed August 9, 2003.

17. Kaplan M and Meier P: Nonparametric estimation from incomplete observations. J Am Stat Assoc 53: 457-481, 1958.

18. Solheim OP, Saeter G, Finnanger AM and Stenwig AE: High-dose methotrexate in the treatment of malignant mesothelioma of the pleura: a phase II study. Br J Cancer 65: 956-960, 1992.

19. Imazawa M, Kojima T, Boku N, et al: Efficacy of sequential methotrexate and 5-fluorouracil (MTX/5FU) in improving oral intake in patients with advanced gastric cancer with severe peritoneal dissemination. Gastric Cancer 12: 153-157, 2009.

20. Ringborg U, Ewert G, Kinnman J, Lundquist PG and Strander H: Methotrexate and 5-fluorouracil in head and neck cancer. Semin Oncol 10 (Suppl 2): 20-22, 1983.

21. Scagliotti GV, Shin DM, Kindler HL, et al: Phase II study of pemetrexed with and without folic acid and vitamin B12 as frontline therapy in malignant pleural mesothelioma. J Clin Oncol 21: 1556-1561, 2003.

22. Jänne PA, Simon GR, Langer CJ, et al: Phase II trial of pemetrexed and gemcitabine in chemotherapy-naive malignant pleural mesothelioma. J Clin Oncol 26: 1465-1471, 2008.

23. Bueno R, Appasani K, Mercer H, Lester S and Sugarbaker D: The alpha folate receptor is highly activated in malignant pleural mesothelioma. J Thorac Cardiovasc Surg 121: 225-233, 2001.

24. Bodmer N, Walters DK and Fuchs B: Pemetrexed, a multitargeted antifolate drug, demonstrates lower efficacy in comparison to methotrexate against osteosarcoma cell lines. Pediatr Blood Cancer 50: 905-908, 2008. 